\title{
COLLISION AVOIDANCE FOR AIRPORT TRAFFIC CONCEPT EVALUATION
}

\author{
Denise R. Jones and Lawrence J. Prinzel, III \\ National Aeronautics and Space Administration, Hampton, VA \\ Sharon D. Otero and Glover D. Barker, Lockheed Martin Mission Services, Hampton, VA
}

\begin{abstract}
An initial Collision Avoidance for Airport Traffic (CAAT) concept for the Terminal Maneuvering Area (TMA) was evaluated in a simulation study at the National Aeronautics and Space Administration (NASA) Langley Research Center. CAAT is being designed to enhance surface situation awareness and provide cockpit alerts of potential conflicts during runway, taxi, and low altitude air-to-air operations. The purpose of the study was to evaluate the initial concept for an aircraft-based method of conflict detection and resolution (CD\&R) in the TMA focusing on conflict detection algorithms and alerting display concepts. This paper gives an overview of the CD\&R concept, simulation study, and test results.
\end{abstract}

\section{Introduction}

The Next Generation Air Transportation System (NextGen) concept for the year 2025 and beyond envisions the movement of large numbers of people and goods in a safe, efficient, and reliable manner [1]. NextGen will remove many of the constraints in the current air transportation system, support a wider range of operations, and deliver an overall system capacity up to three times that of current operating levels. Emerging NextGen operational concepts [2], such as four-dimensional trajectory (4DT) - based airborne and surface operations, equivalent visual operations, and super density arrival and departure operations, represent a different approach to air traffic management and as a result, a dramatic shift in the tasks, roles, and responsibilities for the flight deck and Air Traffic control (ATC) to ensure a safe, sustainable air transportation system.

NASA has initiated a Collision Avoidance for Airport Traffic (CAAT) research topic to develop technologies, data, and guidelines to enable conflict detection and resolution (CD\&R) in the Terminal Maneuvering Area (TMA) under current and emerging NextGen operating concepts. The goal of CAAT is to provide an additional, protective safety layer of CD\&R for NextGen TMA operations. CAAT builds on substantial NASA research and testing for surface operations situation awareness and runway incursion conflict detection and alerting (i.e., the Runway Incursion Prevention System) [3, $4,5,6]$. The concepts use cockpit display designs to promote surface situation awareness, tailored for NextGen operations, and associated CD\&R concepts for safety assurance. The concepts employ continual own-ship and traffic data monitoring and algorithms to detect conflicts on the runway, at low altitudes near the airport, and during taxi and ramp operations for multiple classes of aircraft and surface vehicles. Alerts designed for flight crew awareness identify potentially hazardous operational conditions that may require immediate flight crew response.

NASA is also investigating the concept of providing enhanced situation relevant information for potential runway safety hazards. These indications are intended to increase the flight crews' situation awareness of traffic that could affect runway safety. Research is being initiated regarding the feasibility of providing resolution advisories for conflicts in the TMA to effectively resolve conflict situations without producing undesired consequences.

A piloted simulation study was conducted to investigate the utility of initial concepts for aircraftbased CD\&R in the TMA. This paper will present an overview of the CD\&R concept, simulation study, and test results. 


\section{System Description}

\section{Simulation Facility}

\section{Flight Deck Simulator}

This research was conducted in the Research Flight Deck (RFD) simulator at NASA Langley Research Center (Figure 1). The simulated aircraft dynamics model was a medium to long-haul commercial passenger aircraft. The RFD configuration is a fixed-based, dual-pilot simulator with a collimated $200^{\circ}$ panoramic out-the-window scene. Operations were conducted at the Chicago O'Hare International (ORD) airport. The out-thewindow scene included realistic taxiways and runways with appropriate markings, airport lighting, and other aircraft in various simulated weather/lighting conditions. The visual acuity of the out-the-window scene was 20/40 (pixels per degree). The RFD was equipped with a $30^{\circ}$ horizontal $\times 24^{\circ}$ vertical field-of-view stroke-onraster head-up display located on the left or captain's side.

As shown in Figure 1, the simulator had four large main instrument panel displays referred to as: (left to right) Pilot's Primary Flight Display (PFD), Pilot's Navigation Display (ND), Co-pilot's ND, and Co-pilot's PFD. The four display panels were Liquid Crystal Displays with 13.25" x 10.5" viewable space at $1280 \times 1024$ resolution. Each display used independent brightness control and had very high readability, contrast ratio and viewing angle specifications resulting in excellent cross cockpit readability. The RFD included a Mode Control Panel, Flight Management System, Control Display Units, and hydraulic side-stick control inceptors.

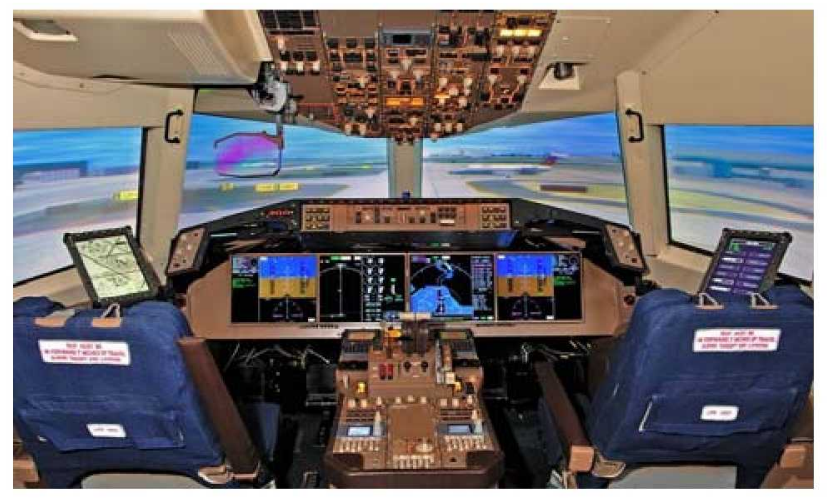

Figure 1. RFD Flight Deck
Two Electronic Flight Bags (EFBs) were installed. Each provided a display resolution of 1024 x 768 with a 10.4" diagonal touch screen display. The EFBs were mounted above and outboard of the side-stick control inceptors near the side window sill. The EFBs utilized a dynamic menu interface using the line select buttons or touch-screen operation. Custom software was developed to provide desired experimental functionality, including Controller Pilot Data-link Communications (CPDLC), airport maps and charts. The airport map page and charts pages displayed standard Federal Aviation Administration (FAA) diagrams that enabled the pilots to zoom and pan utilizing available buttons on the interface.

Traffic position data was "broadcast" at a $1 \mathrm{~Hz}$ rate. No additional latency in traffic position was used. Own-ship position data was updated at a $\mathbf{5 0}$ $\mathrm{Hz}$ rate. Positional error was not introduced into these data. An ATC environment was simulated using data-link messages for own-ship instructions. The ATC messages were triggered based on specific events and timings to coincide with the task scenario. Auditory ATC communications were not used for this study; therefore, instructions for other traffic were not available to the Evaluation Pilots (EPs).

\section{Flight Deck Displays}

The PFD, ND, and Engine Indication and Crew Alerting System display (EICAS) were modeled after Boeing 787, Gulfstream G550 and Airbus A350 instrument panels as current state-ofthe-art production aircraft. Additions from this baseline were made to accommodate CAAT surface and airborne traffic and route awareness.

\section{Primary Flight Display}

The PFD included an ATC message area (CPDLC message area; Figure 2) on the outboard third of the display unit showing incoming and outgoing ATC data-link communications in textual format. Incoming messages were color-coded green while outgoing messages were white. All messages were time-stamped. The captain's inboard display unit showed navigation and EICAS displays. 


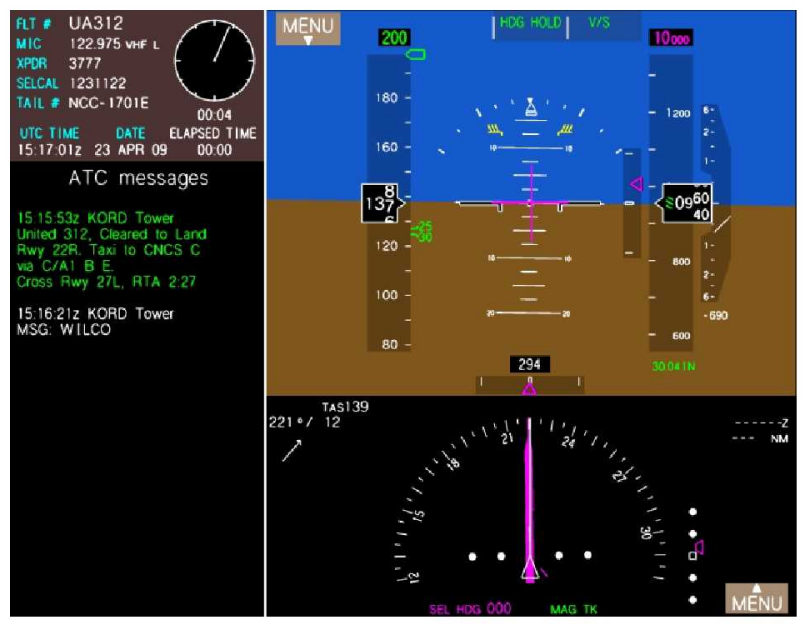

Figure 2. Primary Flight Display

\section{Navigation Display}

The first officer's inboard display was a fullscreen moving map navigation display with high airport surface detail. Unlike today's equipage, surface and airborne traffic icons were included to simulate an Automatic Dependent Surveillance Broadcast (ADS-B)-In environment. This display automatically transitioned to the surface map display (described below) after landing, when the ground speed was less than $80 \mathrm{kt}$.

\section{Electronic Flight Bag Display}

The EFB was used as a flight crew's interface for ATC data-link communications, approach chart, and airport diagram chart references. The CPDLC functionality was modeled after existing commercial aircraft vendor interfaces.

\section{Surface Map Display}

The surface map display (Figure 3) was an enhanced version of the track-up navigation display. The surface map was automatically displayed on the ND during the landing rollout or it could also be manually selected at any time.

Traffic locations were shown on the map. The design largely reflects current RTCA Special Committee (SC)-183 working group findings with regard to element shape and color assignments, and was designed for strategic use for surface operations. For instance, the traffic icons were displayed as medium tan colored chevrons when on the surface and cyan when airborne. The own-ship icon was a large white chevron, and the cleared taxi route was shown in magenta.
A list of aircraft position and associated state data was shown on the right side of the display. This traffic list was sorted by proximity to own-ship with the closest traffic listed first. A cursor control device could be used to select specific traffic in the list (magenta box indicated selected traffic) which then displayed additional details of the selected traffic (lower right of Figure 3). Traffic details included: type, flight ID, speed, heading, ATC assigned route (intent), and the range / bearing from own-ship position. The own-ship's assigned taxi route was displayed on the lower center of the display as a text string, and current position along that route was highlighted in magenta. The EPs had the capability to change the scale of the surface map as desired with the lowest setting of $0.5 \mathrm{~nm}$.

Traffic conflict indications and alerts were displayed on the surface map and are described in detail below.

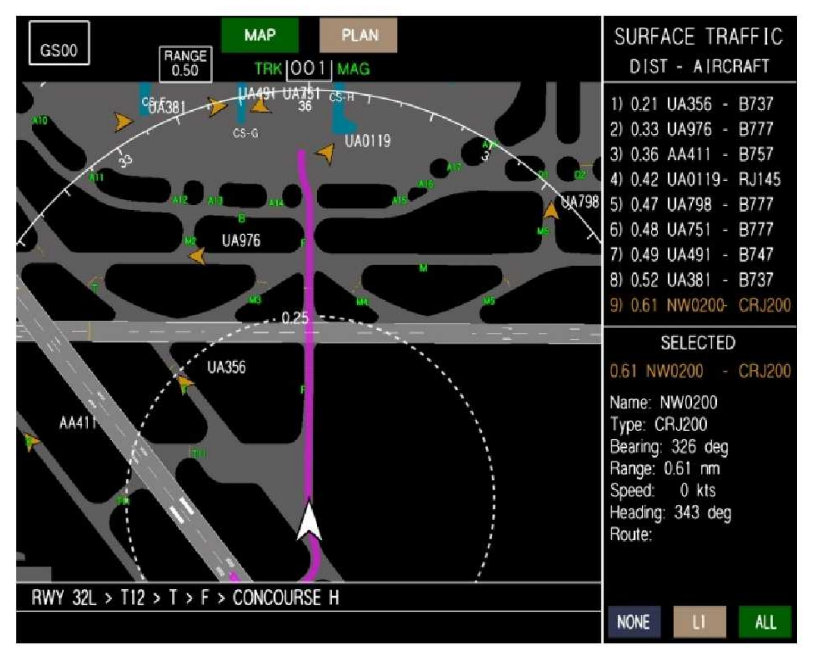

Figure 3. Surface Map Display

\section{Flight Deck Traffic Indications and Alerts}

The concepts for traffic indications and alerts were based on RTCA SC-186 Working Group (WG)-1. This sub-committee is developing an application description for flight deck-based indication and alerting of actual or potential traffic conflicts in the runway environment. The application description was not finalized as this study was planned; therefore, the definition of indications as specified in a draft version of the document [7] was utilized. 


\section{Traffic Indications}

Indications are intended to identify to the flight crew a normal operational condition that could become a runway safety hazard. Two types of indications are defined.

Secondary indications (SI) are provided if there could be a potential collision hazard in the immediate future. SIs are intended to increase the flight crews' situation awareness about relevant traffic that could affect runway safety. If appropriately cleared, the flight crew may proceed with the runway operation.

A SI was indicated on the surface map by an enlarged traffic symbol for the relevant traffic and an identification tag that showed flight ID and ground speed in knots. A status message was also displayed in white text that indicated the relative location of the traffic, e.g., "Traffic Approaching 22L". In the event the traffic symbol was not displayed on the surface map due to the current map scale setting, an off-scale symbol was pegged on the edge of the display in the direction of the traffic.

Primary indications (PI) are provided if the own-ship's current runway or the runway that ownship is immediately heading toward is not usable for entering, takeoff, or landing. A collision hazard would result if own-ship were to use that runway. Before proceeding with crossing, entering, taxi, take-off, or landing on a runway, the crew should ensure that they have the appropriate clearance and that the indicated traffic is no factor.

A PI was indicated on the surface map (Figure 4) in the same manner as a SI with the addition of a blue and white dashed line around the relevant runway.

\section{Conflict Alerts}

Alerts are intended to attract the attention of the flight crew to non-normal traffic conditions and to facilitate timely response to avoid a collision. A two-level alerting scheme is employed.

Caution alerts are generated for conditions that require immediate flight crew awareness and subsequent flight crew response.

A caution alert was indicated on the surface map (Figure 5) by an enlarged yellow traffic symbol surrounded by a yellow circle for the

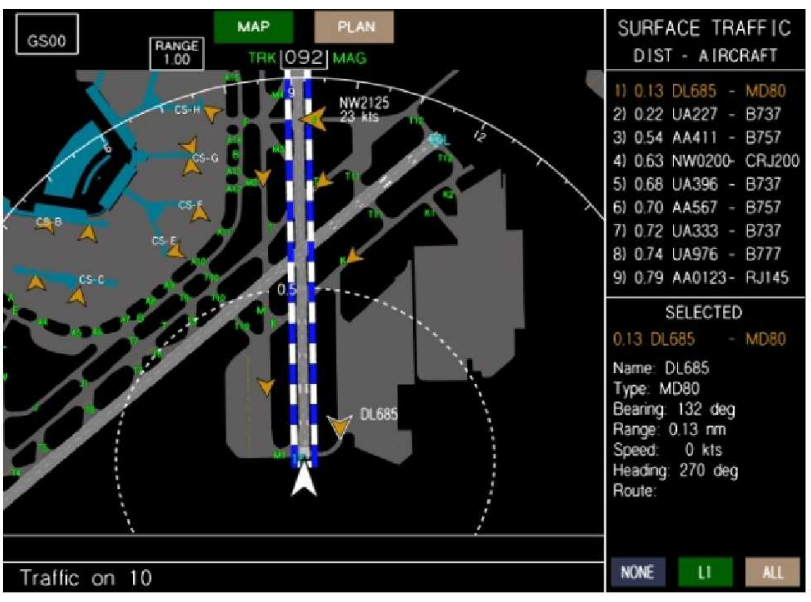

Figure 4. Surface Map showing Primary Indication

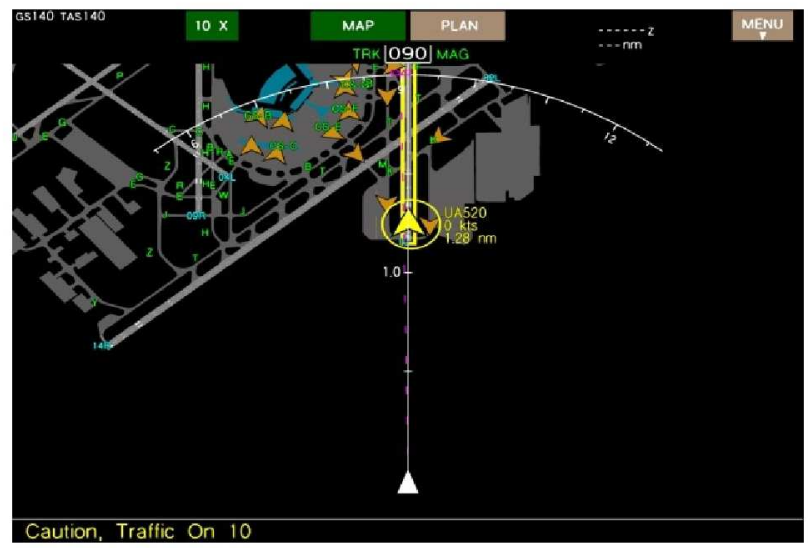

Figure 5. Surface Map showing Caution Alert

relevant traffic; an identification tag that showed flight ID, ground speed in knots, and distance between the own-ship and traffic in nautical miles $(\mathrm{nm})$; and a yellow line around the relevant runway, if applicable. An alert message (shown at the bottom of Figure 5) was displayed in yellow text and was annunciated in the flight deck. The alert message included the relative location of the traffic. An off-scale symbol was displayed if the traffic was outside of the map viewing area due to the selected map scale.

Warning alerts are generated for conditions that require immediate flight crew awareness and immediate flight crew response.

A warning alert was indicated in the same manner as for a caution alert, except the warning was associated with the color red and a square was used to surround the traffic symbol (Figure 6). 


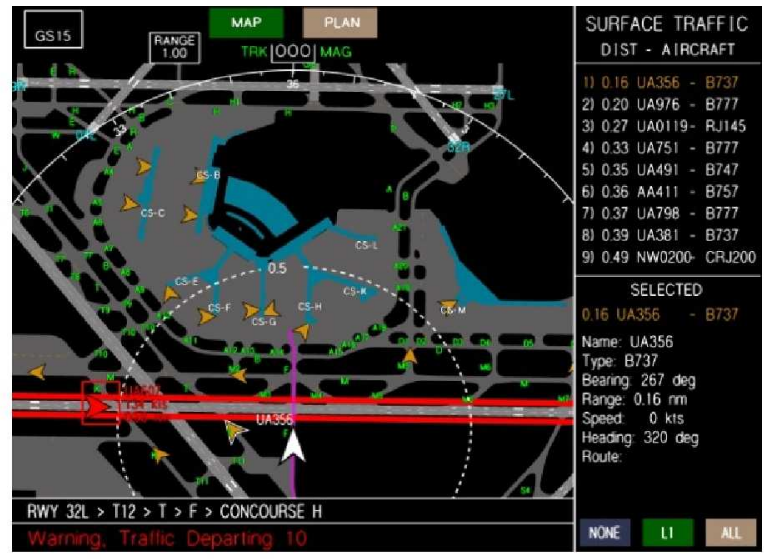

Figure 6. Surface Map showing Warning Alert

\section{Conflict Detection}

Two methods of conflict detection were evaluated during the simulation study.

The Airport Traffic Collision Avoidance Monitor (ATCAM) detects potential traffic conflicts at low altitudes near the airport, on the runway, and during taxi and ramp operations for multiple classes of aircraft and surface vehicles. ATCAM currently generates caution and warning alerts without resolutions.

ATCAM is comprised of three separate aircraft-based algorithms that rely on target state information that can be obtained from various sources such as ADS-B or Traffic Information Service-Broadcast (TIS-B).

1. The Runway Safety Monitor (RSM) is designed to detect and alert for runway conflicts. RSM monitors own-ship and traffic located in a three-dimensional virtual zone around the relevant runway. The operational state of own-ship and traffic, positions within the runway zone, and separation and closure rate are used to determine whether an alert will be generated. RSM is described in detail in [8].

2. The Low Altitude Conflict Monitor (LACM) is designed to detect and alert for air-to-air conflicts near the airport at altitudes below $1000 \mathrm{ft}$ to not conflict with the Traffic Alert and Collision Avoidance System (TCAS). LCAM computes closing speed, time to closest point of approach, time to co-altitude, and other data between ownship and approaching aircraft to determine if criteria and thresholds are met for issuing alerts, similar to the TCAS approach.
3. The Taxi Conflict Monitor (TCM) is designed to detect and alert for ground taxi conflicts anywhere in the airport movement and ramp areas. The TCM initial design is similar to that of LACM and computes distances between own-ship and traffic, closing speeds, time to closest point of approach and utilizes other parameters for alert criteria.

The three are algorithms independent but are integrated and share data to increase the probability of detection for all possible conflicts during airport operations. RSM has been through extensive testing $[3,4,5,6]$, however, LACM and TCM are in the initial development stage. Green, et. al. [9] provides a detailed description of ATCAM including initial alerting criteria.

The second incursion detection method was based on implementation examples generated as part of the application description being developed by RTCA SC-186 WG-1. As mentioned above, the application description was not finalized as this study was planned; therefore, examples specified in a draft version of the document [7] were utilized. A CD\&R algorithm was not developed but scenarios were set-up and indications and alerts were triggered based on the RTCA implementation examples. In general, the RTCA committee is recommending that caution alerts occur 16 to 35 seconds prior to a conflict and warning alerts occur 15 seconds or less prior to a conflict.

\section{Test Method}

Data collection occurred for several different scenarios and test conditions as described below.

\section{Test Scenarios}

Runway, taxi, and low altitude air-to-air conflict scenarios were evaluated. If a warning alert was issued, the EP was trained to abort during departure, go-around on approach, and stop during taxi. The EP was not required to take action when an indication or caution alert was issued. Stationary traffic was positioned at various locations on the airport.

Every effort was made to produce similar timing for the scenarios; however, a certain amount of variability was naturally introduced due to the 
maneuvering conducted by the EP (i.e., deceleration rate, taxi speed, etc.).

\section{Runway Scenario - Arrival / take-off hold}

This scenario tested the incursion situation where an aircraft was in position and holding for departure clearance while another aircraft was approaching the same runway for a landing. The own-ship was approaching Runway $10,4 \mathrm{~nm}$ from the threshold at $1330 \mathrm{ft}$ above field level (AFL) and at an indicated airspeed of $138 \mathrm{kt}$. The EP was instructed to land. The traffic was initially at the Runway 10 hold line nearest to the runway threshold. The traffic taxied into position on the active runway at the start of the simulation run and held in that location.

\section{Runway Scenario - Take-off hold / arrival}

This scenario again tested the situation where one aircraft was in position and holding for departure clearance while another aircraft was approaching the same runway for a landing. In this instance, however, the traffic was approaching Runway 14R, $5 \mathrm{~nm}$ from the threshold at $1650 \mathrm{ft}$ AFL and at an indicated airspeed of $138 \mathrm{kt}$. Ownship was initially located at the Runway 14R hold line nearest to the runway threshold. The EP was cleared into position on the active runway at the start of the simulation run. The EP held in that location awaiting departure clearance.

\section{Runway Scenario - Departure / taxi}

This scenario tested the incursion situation where an aircraft is on departure and another aircraft crosses the runway in front of departing traffic. Own-ship was in position and holding on Runway 10 awaiting departure. The traffic was holding on Taxiway $\mathrm{F}$ at Runway 10 . The EP was cleared for departure. Once the EP initiated departure (power lever angle $>7^{\circ}$ ) the traffic crossed the runway.

\section{Runway Scenario - Taxi / departure}

This scenario again tested the situation where an aircraft is on departure and another aircraft crosses the runway in front of departing traffic. In this instance, however, own-ship was initially on Taxiway T12 as if just exited from Runway 14R. The traffic was located in position and holding on Runway 10 for departure. The EP taxied at $15 \mathrm{kt}$ and was cleared to taxi to Concourse $H$ via $T 12, T$, $\mathrm{F}$ and cleared to cross Runway 10. When the own- ship was $900 \mathrm{ft}$ from Runway 10, the traffic began its departure.

\section{Runway Scenario - Arrival / arrival same runway}

In this scenario, own-ship was approaching Runway 28 , initially $4 \mathrm{~nm}$ from the threshold at $1330 \mathrm{ft}$ AFL and at an indicated airspeed of $138 \mathrm{kt}$. Another aircraft was approaching Runway 28 ahead of own-ship, initially $1 \mathrm{~nm}$ from the threshold at $370 \mathrm{ft}$ AFL and an indicated airspeed of $138 \mathrm{kt}$. The traffic landed and was slow to exit the runway.

Taxi Scenario - Exiting runway / taxi traffic

This scenario tests the situation where an aircraft exits the runway and conflicts with traffic on a parallel taxiway. Own-ship had just touched down on Runway 10 and was cleared to taxi to Concourse $\mathrm{K}$ via M6, D, A17. Traffic was taxiing on Taxiway $M$ toward Runway 22L. The taxi traffic conflicts with own-ship as the EP exited the runway at M6.

Taxi Scenario - Traffic ahead

This scenario tests the situation where an aircraft exhibits excessive closure on traffic from behind. Own-ship was taxiing on Taxiway $T$ toward Runway 14R at a ground speed of $25 \mathrm{kt}$. The traffic was also taxiing on Taxiway $T$ toward Runway 14R ahead of the own-ship at a ground speed of $15 \mathrm{kt}$.

\section{Taxi Scenario - Traffic behind}

This scenario also tests the situation where an aircraft closes on traffic from behind. In this instance, the own-ship was taxiing on Taxiway $T$ toward Runway $14 \mathrm{R}$ at a ground speed of $15 \mathrm{kt}$. Traffic was taxiing on Taxiway $\mathrm{T}$ toward Runway $14 \mathrm{R}$ behind own-ship at a ground speed of $20 \mathrm{kt}$.

\section{Taxi Scenario - Taxi in ramp}

This scenario tests the situation where two aircraft conflict in the ramp area. Own-ship was cleared to taxi to Runway 28 from Concourse $G$ via F, M, M7. Traffic was taxiing from Concourse $\mathrm{H}$ via Taxiway $F$. A conflict occurred near the entrance to Taxiway $F$.

\section{Taxi Scenario - Traffic head-on}

This scenario tests the situation where two aircraft conflict head-on on a taxiway. Own-ship had just touched down on Runway 28 and had been cleared to taxi to Concourse E via T, A9. Traffic was taxiing on Taxiway $\mathrm{T}$ toward Runway 28 . A 
conflict occurred on Taxiway $\mathrm{T}$ between Taxiways $\mathrm{T} 10$ and $\mathrm{M}$.

\section{Low Altitude Air-to-air Scenario - Arrival / crossing traffic}

This scenario tests the situation where an aircraft in on final approach and traffic crosses its path. Own-ship was on approach to Runway 14R, 2 $\mathrm{nm}$ from the threshold at $700 \mathrm{ft}$ AFL and at an indicated airspeed of $138 \mathrm{kt}$. Traffic was traveling at heading $050,1 \mathrm{~nm}$ back and $1 \mathrm{~nm}$ right of Runway 14R threshold at an indicated airspeed of $138 \mathrm{kt}$. As own-ship approached the runway, the traffic crossed own-ship's path.

\section{Evaluation Pilots}

Twenty-four pilots served as participants for the research, representing twelve flight crews. Each crew flew for a major U.S. air carrier and was paired by airline to ensure crew coordination and cohesion with regard to terminal and surface operational procedures. The Captains had an average of over 14,000 flight hours with 19 years of commercial flying experience. The first officers had an average of over 10,000 flight hours with 13 years of commercial experience. All pilots were required to have "glass cockpit" experience. The Captain was the designated pilot flying throughout all the trials and the First Officer served as the monitoring pilot (pilot-not-flying). The flight crews were asked to maintain good crew resource management and comply with company specific procedures.

\section{Test Matrix}

This study evaluated the indication and alert timeliness based on ATCAM and RTCA alerting criteria during runway, taxi, and low altitude air-toair conflicts. The effectiveness of indications and alerts were also evaluated through EP ratings.

Each EP evaluated the runway conflict scenarios three times per scenario. The EPs expected a conflict event but were not aware of the exact type of conflict prior to the first run.

On the first run, the EPs were shown alerts using the ATCAM algorithm as the alert source. Indications were not shown. On the second run, the EPs were shown indications and alerts based on ATCAM criteria. This allowed the EPSs to evaluate the effectiveness of indications. On the third run, the EPs were shown indications and alerts based on RTCA criteria. This allowed the EPs to evaluate ATCAM criteria versus RTCA criteria.

The runway conflict scenarios were grouped together and given in different order by flight crew. The EPs then evaluated the taxi and low altitude air-to-air scenarios one time each in random order per flight crew. It should be noted that during the test runs, the EPs were asked to continue the maneuver until the warning alert was received for evaluation purposes. All test runs were conducted in $\mathrm{VMC}$ conditions $(3 \mathrm{~nm}$ visibility and $1000 \mathrm{ft}$ ceiling) without winds. Pilot reaction to conflict events was not evaluated in this study.

\section{Procedure}

Each EP participated in a briefing and training session prior to data collection. The EP was trained on the conflict alerting concept using scenarios different from those used during data collection. Before each run, the pilots were briefed on the run conditions (approach, departure, or taxi), alerting system selected (ATCAM or RTCA), and displays available (alerts only or indications and alerts). Post-run, post-block, and post-test questionnaires were administered. Audio, video, and digital data were also recorded.

\section{Results}

A summary of quantitative and qualitative results is presented. All test runs included conflict events. All data is referenced from the center of gravity (CG) of the aircraft.

\section{Results by Scenario}

Each flight crew conducted 24 test runs (288 total). The results are presented by scenario.

The timeliness of indications and alerts were rated on a scale of 1 to 10 with 1 being "too early" and 10 being "too late". The usefulness of the alerts were rated on a scale of 1 to 10 with 1 being "completely useless" and 10 being "completely useful". Ratings for most other queries were based on a 10 point scale with 1 equivalent to "strongly disagree" and 10 being "strongly agree". Indications and RTCA alerting were only evaluated for runway conflict scenarios. 


\section{results}

Runway Scenario - Arrival / take-off hold

For this approach scenario, a SI was not displayed. During 24 test runs (48 EP ratings), only 12 EPs (25 percent) thought that a SI was not displayed, 30 EPs (62.5 percent) indicated a SI was displayed, and 6 EPs (12.5 percent) did not know if a SI was shown.

A PI was displayed. Of $48 \mathrm{EP}$ ratings, $43 \mathrm{EPs}$ (89.6 percent) indicated a PI was displayed, 1 EP (2.1 percent) indicated a PI was not displayed, and 4 EPs ( 8.3 percent) did not know. The PI was reported to occur in a timely manner (Table 1 ).

Indications were deemed helpful in determining critical runway safety information (mean 8.2, standard deviation (SD) 1.6), helpful in determining the location and movement of traffic that was relevant to the safety of the own-ship (mean 8.4, SD 1.7), and beneficial in this situation (mean 8.6, SD 1.7).

The ATCAM caution alert and RTCA caution alert occurred at approximately the same point which was reported as being timely (Table 1). However, the ATCAM warning alert occurred earlier and was rated as being more timely than the RTCA warning alert for this scenario.
Of 24 EP ratings, 19 EPs (79 percent) indicated that the ATCAM alerting provided the greatest amount of conflict prevention awareness, no EPs indicated RTCA, and 5 EPs (21 percent) indicated both methods of alerting were equivalent. Of 24 EP ratings, 18 EPs ( 75 percent) preferred the indication and ATCAM alerting combination for this conflict situation, 2 EPs (8 percent) preferred indications and RTCA alerting, and 4 EPs (17 percent) indicated both methods were equivalent.

\section{results}

Runway Scenario - Take-off hold / arrival

A SI was displayed for this scenario and reported to occur in a timely manner (Table 2). During 24 test runs (48 EP ratings) 46 EPs (95.8 percent) indicated a SI was displayed, 2 EPs (4.2 percent) did not know if a SI was displayed, and none of the EPs indicated a SI was not displayed.

A PI was not displayed. Of 48 EP ratings, only 19 EPS (39.6 percent) indicated a PI was not displayed, 22 EPs (45.8 percent) indicated a PI was displayed, and 7 EPs (14.6 percent) did not know.

Indications were deemed helpful in determining critical runway safety information (mean 7.7, SD 1.7), helpful in determining the location and movement of traffic that was relevant to the safety of the own-ship (mean 7.5, SD 1.4), and beneficial in this situation (mean 8.5, SD 1.4).

Table 1. Indication and Alert Data for Arrival / Take-off Hold Runway Scenario

\begin{tabular}{|l|c|c|c|c|c|}
\hline \multicolumn{1}{|c|}{ Type } & $\begin{array}{c}\text { Distance to } \\
\text { traffic (nm) }\end{array}$ & $\begin{array}{c}\text { Time to traffic } \\
\text { (seconds) }\end{array}$ & AFL (feet) & $\begin{array}{c}\text { Timeliness } \\
\text { (mean / SD) }\end{array}$ & $\begin{array}{c}\text { Usefulness } \\
\text { (mean / SD) }\end{array}$ \\
\hline PI & 3.0 & not available & 950 & $5.1 / 1.1$ & $7.3 / 2.1$ \\
\hline ATCAM caution & 1.4 & 35 & 490 & $5.8 / 1.1$ & $7.5 / 2.2$ \\
\hline ATCAM warning & 1.0 & 26 & 325 & $6.1 / 1.5$ & $8.5 / 1.6$ \\
\hline RTCA caution & 1.4 & 35 & 418 & $6.5 / 1.4$ & $7.8 / 1.6$ \\
\hline RTCA warning & 0.6 & 15 & 183 & $8.6 / .1 .3$ & $6.9 / 2.5$ \\
\hline
\end{tabular}

Table 2. Indication and Alert Data for Take-off Hold / Arrival Runway Scenario

\begin{tabular}{|l|c|c|c|c|}
\hline \multicolumn{1}{|c|}{ Type } & $\begin{array}{c}\text { Distance to } \\
\text { traffic }(\mathbf{n m})\end{array}$ & $\begin{array}{c}\text { Time to conflict } \\
\text { (seconds) }\end{array}$ & $\begin{array}{c}\text { Timeliness } \\
\text { (mean / SD) }\end{array}$ & $\begin{array}{c}\text { Usefulness } \\
\text { (mean / SD) }\end{array}$ \\
\hline SI & 3.0 & not available & $5.7 / 1.4$ & $7.6 / 2.0$ \\
\hline ATCAM caution & 2.2 & 55 & $5.8 / 1.3$ & $7.3 / 2.4$ \\
\hline ATCAM warning & 1.2 & 29 & $6.7 / 1.6$ & $6.6 / 3.0$ \\
\hline RTCA caution & 1.4 & 35 & $6.5 / 1.7$ & $6.8 / 2.8$ \\
\hline RTCA warning & 0.6 & 15 & $7.9 / 1.6$ & $6.5 / 3.4$ \\
\hline
\end{tabular}


Table 3. Indication and Alert Data for Departure Taxi Runway Scenario

\begin{tabular}{|l|c|c|c|c|c|}
\hline \multicolumn{1}{|c|}{ Type } & $\begin{array}{c}\text { Distance to } \\
\text { traffic }(\mathbf{n m})\end{array}$ & $\begin{array}{c}\text { Time to conflict } \\
\text { (seconds) }\end{array}$ & $\begin{array}{c}\text { Ground } \\
\text { Speed (kt) }\end{array}$ & $\begin{array}{c}\text { Timeliness } \\
\text { (mean / SD) }\end{array}$ & $\begin{array}{c}\text { Usefulness } \\
\text { (mean / SD) }\end{array}$ \\
\hline PI & $\mathbf{0 . 9}$ & not applicable & 0 & $5.5 / 1.0$ & $7.2 / 2.2$ \\
\hline ATCAM warning & $\mathbf{0 . 9}$ & 37 & 7 & $5.5 / 1.6$ & $8.1 / 2.3$ \\
\hline RTCA warning & $\mathbf{0 . 8}$ & 24 & 41 & $7.5 / 1.6$ & $6.0 / 3.0$ \\
\hline
\end{tabular}

The ATCAM caution and warning alert were rated as being slightly more timely than the RTCA caution and warning alert (Table 2); however, both were rated as occurring somewhat late. In this situation, the EPs indicated that there was not really any action to take other than calling ATC or the conflict traffic.

Of 23 EP ratings, 14 EPs (61 percent) indicated that the ATCAM alerting provided the greatest amount of conflict prevention awareness, 2 EPs ( 9 percent) indicated RTCA, and 7 EPs (30 percent) indicated both methods of alerting were equivalent. Of $24 \mathrm{EP}$ ratings, $16 \mathrm{EPs}$ (67 percent) preferred the indication and ATCAM alerting combination for this conflict situation, 3 EPs (12 percent) preferred indications and RTCA alerting, and 5 EPs (21 percent) indicated both methods were equivalent.

\section{Runway Scenario - Departure / taxi results}

A SI was not displayed for this scenario. During 24 test runs (48 EP ratings), 29 EPs (60.4 percent) were aware that a SI was not displayed, 5 EPs (10.4 percent) indicated a SI was displayed and 14 EPs (29.2 percent) did not know.

A PI was displayed when the own-ship was stationary and the traffic crossed the hold line (Table 3). Of 48 EP ratings, 29 EPs (60.4 percent) indicated a PI was displayed, 10 EPs (20.8 percent) indicated a PI was not displayed, and 9 EPs (18.8 percent) did not know. The PI was indicated to occur in a timely manner.

Indications were deemed helpful in determining critical runway safety information (mean 7.6, SD 2.4), helpful in determining the location and movement of traffic that was relevant to the safety of the own-ship (mean 7.2, SD 2.3), and beneficial in this situation (mean 7.4, SD 2.7).

A caution alert was not generated for this scenario. For the ATCAM alerting test runs, out of
24 EP ratings, 19 EPs (79.2 percent) indicated a caution alert was not generated, 2 EPs (8.3 percent) indicated a caution alert did occur, and 3 EPs (12.5 percent) did not know. For the RTCA alerting test runs, only $1 \mathrm{EP}$ (4.2 percent) indicated a caution alert was displayed, the other 23 EPs (95.8 percent) indicated a caution alert was not displayed.

The ATCAM warning alert occurred much earlier and in a more timely manner (Table 3 ) than the RTCA warning alert. Due to the criteria specified for display of the RTCA warning alert (own-ship departing ( $>40 \mathrm{kt}$ ) and traffic crossed hold line), the alert was only displayed during three test runs.

Of 24 EP ratings, 20 EPs (83.3 percent) indicated that the ATCAM alerting provided the greatest amount of conflict prevention awareness, no EPs indicated RTCA, and 4 EPs (16.7 percent) indicated both methods of alerting were equivalent. Of 23 EP ratings, 19 EPs (82.6 percent) preferred the indication and ATCAM alerting combination for this conflict situation, 2 EPs (8.7 percent) preferred indications and RTCA alerting, and 2 EPs (8.7 percent) indicated both methods were equivalent.

\section{Runway Scenario - Taxi / departure results}

ATCAM is designed to provide early warning of an impending runway conflict during taxi, based on the aircraft taxi speed. If the own-ship is traveling $8 \mathrm{kts}$ or greater and is not slowing down, the alert will be generated before the aircraft reaches the hold line, providing sufficient distance to stop before crossing the hold line. As the taxi speed increases, the alert is generated when the own-ship is a farther distance from the hold line. When the own-ship is traveling less than $8 \mathrm{kt}$, the alert is not generated until after the own-ship crosses the hold line. The $8 \mathrm{kt}$ threshold was used to prevent false or nuisance alerts as the own-ship taxis toward a hold line. 
For this scenario, it is important to note that the distance from the runway centerline to the runway edge is $75 \mathrm{ft}$, the distance from the runway edge to the hold line is $290 \mathrm{ft}$, and the distance from the own-ship CG to the nose is $72.8 \mathrm{ft}$. The EP was asked to taxi the aircraft at $15 \mathrm{kt}$. A SI was displayed for this scenario in a timely manner (Table 4). Of 48 EP ratings, only 23 EPs (47.9 percent) were aware that a SI was displayed, 16 EPs (33.3 percent) indicated a SI was not displayed and 9 EPs (18.8 percent) did not know.

A PI was displayed if the traffic was departing $(>40 \mathrm{kt})$ and the own-ship had not crossed the hold line. During the ATCAM alerting test runs, a PI was only displayed before the caution alert on 6 of the 12 runs. This was due to the fact the ATCAM generated alerts is a predictive manner and the caution alert occurred before the criteria was met for the PI. Of $24 \mathrm{EP}$ ratings, only $9 \mathrm{EPs}(37.5$ percent) identified the display of the PI correctly for these test runs. During the RTCA alerting test runs, a PI was displayed on 11 of 12 runs. Of $24 \mathrm{EP}$ ratings, $18 \mathrm{EPs}$ ( 75 percent) identified the display of the PI correctly for these runs. The PI was rated as occurring somewhat late (Table 4).

Indications were deemed helpful in determining critical runway safety information (mean 7.4, SD 1.8), helpful in determining the location and movement of traffic that was relevant to the safety of the own-ship (mean 7.8, SD 1.6), and beneficial in this situation (mean 8.0, SD 2.3).

A caution alert was not generated for this scenario. For the ATCAM alerting test runs (24 EP ratings), 17 EPs (70.8 percent) indicated a caution alert was not generated, 3 EPs (12.5 percent) indicated a caution alert did occur, and 4 EPs (16.7 percent) did not know. For the RTCA alerting test runs (24 EP ratings), 17 EPs (70.8 percent) indicated a caution alert was not displayed, 1 EP (4.2 percent) indicated a caution alert was displayed, and 6 EPs ( 25 percent) did not know.

The ATCAM warning alerts were rated as occurring in a more timely manner than the RTCA alerts (Table 4). Due to the predictive alerting, the ATCAM warning alert occurred prior to reaching the hold line. The RTCA warning alert was not displayed until the own-ship had crossed the hold line and the traffic was departing ( $>40 \mathrm{kt}$ ) which the EPs indicated was too late.

Of 24 EP ratings, 19 EPs (79 percent) indicated that the ATCAM alerting provided the greatest amount of conflict prevention awareness, 1 EP (4 percent) indicated RTCA, and 4 EPs (21 percent) indicated both methods of alerting were equivalent. Of $24 \mathrm{EP}$ ratings, $18 \mathrm{EPs}$ (75 percent) preferred the indication and ATCAM alerting combination for this conflict situation, 2 EPs (8 percent) preferred indications and RTCA alerting, and 4 EPs (17 percent) indicated both methods were equivalent.

\section{Runway Scenario - Arrival / arrival same runway results \\ For this approach scenario, a SI was not} displayed. During 24 test runs (48 EP ratings), only 10 EPS (20.8 percent) thought that a SI was not displayed, 31 EPs (64.6 percent) indicated a SI was displayed, and 7 EPs (14.6 percent) did not know if a SI was shown.

A PI was displayed. Of $48 \mathrm{EP}$ ratings, $44 \mathrm{EPs}$ (91.7 percent) indicated a PI was displayed, 2 EPs (4.2 percent) indicated a PI was not displayed, and 2 EPs (4.2 percent) did not know. The PI was indicated to occur in a timely manner (Table 5).

Table 4. Indication and Alert Data for Taxi / Departure Runway Scenario

\begin{tabular}{|l|c|c|c|}
\hline \multicolumn{1}{|c|}{ Type } & $\begin{array}{c}\text { Distance from } \\
\text { hold line (feet) }\end{array}$ & $\begin{array}{c}\text { Timeliness } \\
\text { (mean / SD) }\end{array}$ & $\begin{array}{c}\text { Usefulness } \\
\text { (mean / SD) }\end{array}$ \\
\hline SI & 630 & $5.3 / 1.0$ & $7.2 / 2.3$ \\
\hline PI & 113 & $6.6 / 1.1$ & $6.0 / 2.3$ \\
\hline ATCAM warning & 111 & $6.5 / 1.3$ & $7.8 / 2.2$ \\
\hline RTCA warning & -5 & $8.6 / 1.4$ & $5.6 / 3.1$ \\
\hline
\end{tabular}


Table 5. Indication and Alert Data for Arrival / Arrival Same Runway Scenario

\begin{tabular}{|l|c|c|c|c|c|}
\hline \multicolumn{1}{|c|}{ Type } & $\begin{array}{c}\text { Distance to } \\
\text { traffic (nm) }\end{array}$ & $\begin{array}{c}\text { Time to traffic } \\
\text { (seconds) }\end{array}$ & AFL (feet) & $\begin{array}{c}\text { Timeliness } \\
\text { (mean / SD) }\end{array}$ & $\begin{array}{c}\text { Usefulness } \\
\text { (mean / SD) }\end{array}$ \\
\hline PI & 3.0 & not available & 1016 & $5.1 / 1.2$ & $7.3 / 1.9$ \\
\hline ATCAM caution & 2.0 & 51 & 463 & $5.4 / 0.5$ & $8.3 / 1.4$ \\
\hline ATCAM warning & 1.8 & 47 & 383 & $4.9 / 1.5$ & $8.0 / 1.7$ \\
\hline RTCA caution & 2.2 & 55 & 516 & $5.7 / 1.0$ & $7.9 / 1.5$ \\
\hline RTCA warning & 1.5 & 39 & 218 & $6.7 / 1.8$ & $7.7 / 2.0$ \\
\hline
\end{tabular}

Indications were deemed helpful in determining critical runway safety information (mean 8.2, SD 1.2), helpful in determining the location and movement of traffic that was relevant to the safety of the own-ship (mean 8.3, SD 1.4), and beneficial in this situation (mean 8.6, SD 1.5).

The ATCAM and RTCA caution alert occurred at approximately the same point which was reported as being timely (Table 5). The ATCAM warning alert occurred slightly earlier and was rated as being slightly more timely than the RTCA warning alert.

Of 24 EP ratings, 12 EPs (50 percent) indicated that the ATCAM alerting provided the greatest amount of conflict prevention awareness, 7 EPs (29 percent) indicated RTCA, and 5 EPs (21 percent) indicated both methods of alerting were equivalent. Of $24 \mathrm{EP}$ ratings, 11 EPs (46 percent) preferred the indication and ATCAM alerting combination for this conflict situation, 8 EPs (33 percent) preferred indications and RTCA alerting, and 5 EPs (21 percent) indicated both methods were equivalent. results

Taxi Scenario - Exiting runway / taxi traffic

The timing for this scenario was somewhat inconsistent due to the manner in which the EP decelerated the aircraft. As a result, the ATCAM caution alert was only generated before a warning alert on 7 out of 12 test runs. Both the ATCAM caution and warning alerts were indicated to occur somewhat late (Table 6).

Taxi Scenario - Traffic ahead results

For this scenario, the EP was asked to taxi at $25 \mathrm{kt}$ in order to over-come the traffic taxiing ahead at $15 \mathrm{kt}$. The ATCAM warning alert was rated as being somewhat late (Table 6).
Taxi Scenario - Traffic behind results

For this scenario, the EP was asked to taxi at $10 \mathrm{kt}$ to $15 \mathrm{kt}$ so the traffic taxiing behind the ownship at $20 \mathrm{kt}$ would gain on own-ship. The ATCAM warning alert was rated as being somewhat late (Table 6).

\section{Taxi Scenario - Taxi in ramp results}

The timing for this scenario was somewhat inconsistent due to the speed in which the EP taxied the aircraft. As a result, the test run had to be repeated for some crews because the alert was not generated on the first attempt. The ATCAM warning alert was rated as being somewhat late (Table 6).

Taxi Scenario - Traffic head-on results

When the ATCAM warning alert occurred (Table 6), there was no place to exit the taxiway before reaching the traffic. From discussions, some pilots indicated they would prefer the alert to occur at a point when there was still the opportunity to exit the taxiway before reaching the traffic. At present, ATCAM cannot alert based on turn locations because taxiway data is not utilized.

Low Altitude Air-to-air Scenario - Arrival / crossing traffic results

The ATCAM caution alert occurred as soon as this scenario began due to the initial location of the conflict traffic; therefore, a true indication of when the caution alert would be generated cannot be determined. The ATCAM warning alert was rated as occurring somewhat late (Table 7).

\section{Qualitative}

Post-run, post-block, and post-test questionnaires were administered when required. Ratings for most of the questions were given on a scale of 1 ("strongly disagree", "completely useless") to 10 ("strongly agree", "completely 
Table 6. Alert Data for Taxi Scenarios

\begin{tabular}{|c|c|c|c|c|}
\hline Type & Distance (feet) & Time (seconds) & $\begin{array}{c}\text { Timeliness } \\
\text { (mean / SD) }\end{array}$ & $\begin{array}{c}\text { Usefulness } \\
\text { (mean / SD) }\end{array}$ \\
\hline \multicolumn{5}{|c|}{ Taxi Scenario exiting runway / taxi traffic results (distance and time to impact reported) } \\
\hline ATCAM caution & 434 & 10 & $7.1 / 1.5$ & $6.9 / 2.3$ \\
\hline ATCAM warning & 257 & 5 & $7.8 / 1.6$ & $6.4 / 2.8$ \\
\hline Taxi Scenario traffic ahead results (distance and time to traffic reported) \\
\hline ATCAM caution & 378 & 15 & $6.0 / 1.5$ & $7.3 / 2.0$ \\
\hline ATCAM warning & 181 & 7 & $6.9 / 1.8$ & $7.3 / 2.4$ \\
\hline Taxi Scenario traffic behind results (distance and time to traffic reported) \\
\hline ATCAM caution & 208 & 15 & $6.4 / 1.6$ & $6.0 / 2.5$ \\
\hline ATCAM warning & 102 & 7 & $7.3 / 1.5$ & $6.1 / 2.4$ \\
\hline Taxi Scenario taxi in ramp results (distance from hold line reported) \\
\hline ATCAM caution & 334 & 15 & $5.6 / 1.1$ & $7.5 / 1.8$ \\
\hline ATCAM warning & 215 & 9 & $7.3 / 1.0$ & $7.6 / 1.7$ \\
\hline Taxi Scenario traffic head-on results (distance and time to impact reported) \\
\hline ATCAM caution & 375 & 10 & $6.7 / 1.5$ & $6.6 / 2.5$ \\
\hline ATCAM warning & 213 & 6 & $7.6 / 1.5$ & $6.0 / 3.2$ \\
\hline
\end{tabular}

Table 7. Alert Data for Arrival / Crossing Traffic Low Altitude Air-to-air Scenario

\begin{tabular}{|c|c|c|c|c|c|}
\hline Type & $\begin{array}{c}\text { Distance } \\
\text { (feet) }\end{array}$ & $\begin{array}{c}\text { Time } \\
\text { (seconds) }\end{array}$ & AFL (feet) & $\begin{array}{c}\text { Timeliness } \\
\text { (mean / SD) }\end{array}$ & $\begin{array}{c}\text { Usefulness } \\
\text { (mean / SD) }\end{array}$ \\
\hline ATCAM caution & $1.0 \mathrm{~nm}$ & 25 & 642 & $6.7 / 1.6$ & $7.5 / 1.6$ \\
\hline ATCAM warning & $0.8 \mathrm{~nm}$ & 19 & 576 & $7.0 / 1.4$ & $7.5 / 2.2$ \\
\hline
\end{tabular}

useful"). The post-test questionnaire was given to the EPs to fill out at their leisure. Twenty-one questionnaires were returned. In general, the EPs indicated they felt slightly safer when indications and alerts were provided (mean 8.6, SD 0.9) than when alerts alone were provided (mean 7.4, SD 1.3).

\section{Indications}

Indications were found to be helpful in determining critical runway safety information (mean 8.0, SD 1.4) and in determining the location and movement of traffic that was relevant to the safety of the own-ship (mean 8.2, SD 1.7). Of 21 EP ratings, 20 EPs (95.2 percent) responded that indications were desired for runway and taxi operations and 19 EPs (90.5 percent) responded that indications were desired for low altitude air-to-air operations. The enlarged chevron (mean 7.9, SD 2.0 ) and the indicated runway (mean 7.5, SD 2.3) were rated as being the most useful for determining relevant traffic. During the testing, it was observed that there was some confusion over the terms SI and PI. This can be evidenced by the data reported above on the EPs lack of awareness of the display of a SI and PI. Primary usually implies initial, however, in this case the SI was the initial indication provided in many situations.

\section{Alerts}

Regarding alert display features, the auditory alert (mean 9.2, SD 1.0) was rated as being most useful, followed by the circle/square surrounding the chevron (mean 8.2, SD 1.1), the indicated runway (mean 7.8, SD 2.4), and the enlarged chevron (mean 7.6, SD 1.8). Of $20 \mathrm{EP}$ ratings, all $20 \mathrm{EPs}$ (100 percent) responded that the audible alert was most likely to bring a conflict situation to their attention. During an alert, the distance between the traffic and own-ship was displayed as part of the traffic ID tag. Of $20 \mathrm{EP}$ ratings, $12 \mathrm{EPs}$ (60 percent) indicated they used this information. There was some discussion related to the method of display. The text for the ID tag was somewhat 
small and was sometimes difficult to see against the surface map background, especially for the red text associated with a warning. It was recommended to perhaps highlight the traffic ID tag or display in another location such as the text message area at the bottom of the surface map. Of 24 EP ratings, 15 EPs (62.5 percent) wanted the distance displayed in nautical miles and 9 EPs (37.5 percent) preferred a combination display (above $1 \mathrm{~nm}$ use nautical miles, below $1 \mathrm{~nm}$ use feet).

Post-experimental paired comparison questionnaires were administered for pilots to evaluate preferences for alerting phraseology for selected conflict scenarios. An Analysis of Variance (ANOVA) was performed followed by a Student-Newman Keuls (SNK) post-hoc test using a 0.05 significance level.

The EPs rated the phrase, "Traffic on 10" the most significantly preferred alert phrase for the runway conflict on arrival scenario. For the runway conflict on departure scenario, the SNK revealed two significant subsets with multiple alert phrases not being significantly different in terms of preferences. The most preferred choices were "Runway Occupied", "Runway Conflict", and "Traffic on 10". It is important to note that "Traffic on 10" was also preferred for runway conflict on arrival suggesting it as the ideal candidate as alert phrase for runway conflicts on departure and arrival. When taxiing across a runway, the post-hoc test revealed three unique subsets of grouping for alert phrases. The top choices were both "Traffic Departing 10" and "Runway Conflict". To reflect the results for runway incursion for departures and arrivals described above, the data purports the best choice to be "Traffic Departing 10" although it is important to note that the ratings were based on a specific conflict scenario.

The EPs also provided paired comparison ratings for alert phrases during taxi conflicts. They significantly rated the alert phrase, "Traffic Converging from Left" for the traffic conflict from the left scenario. For the head-on taxi conflict scenario, the EPs uniquely rated "Traffic Ahead", as the top choice for the taxiway conflict scenario. Taken together, these results evince that directional information on taxiway conflict aircraft (e.g., "Traffic Ahead") provides the best information to the pilot and was most preferred. Experimental research to confirm these ratings are needed to validate these findings.

The low altitude air-to-air scenario involved an aircraft that was on arrival during the same time that other traffic was crossing on approach for landing. The paired comparison procedure includes a statistic that checks for internal consistency of pilot responses to ensure that the pilot ratings were reasonable across alert phrase preferences. Unfortunately, the statistics demonstrated a statistically significant dissociation with intra-pilot response. Therefore, only descriptive analysis of EP phrase preference was available for this scenario (Table 8).

Table 8. Alert Phrase Preference for Low Altitude Air-to-Air Scenario

\begin{tabular}{|c|l|}
\hline No. of EP & Phrase \\
\hline 6 & Traffic Right and Below \\
\hline 6 & Traffic Converging from Right \\
\hline 6 & Traffic 2 O' clock \\
\hline 3 & Conflict \\
\hline 2 & Traffic Converging \\
\hline 1 & Traffic Converging Ahead \\
\hline
\end{tabular}

Directive Alerting

The EPs were queried whether directive alerts, in which information is provided on how to resolve the imminent conflict, were desired for runway, taxi, and low altitude air-to-air operations. Of 24 EP ratings, Table 9 shows that directive alerts are desired for low altitude air-to-air (19 EPs, 79.2 percent) and runway conflicts on approach (17 EPs, 70.8 percent). Approximately half of the EPs indicated directive alerts were desired for runway conflicts on departure and when taxiing across a runway. Directive alerts were not desired for taxi conflicts. Of 24 EP ratings, 19 EPs (79.2 percent) would prefer the directive alert before the alert message (e.g,. "Go around, Traffic on 10"), 4 EPs (16.7 percent) would prefer the directive after the alert message (e.g., "Traffic on 10, Go around"), and 1 EP (4.2 percent) would prefer the directive alone, without an alert message (e.g., "Go around"). The preferred directive for the different operational phases were: "go around" during approach, "abort" during departure, "stop" during taxi, and "climb" or "go around" during low altitude operations. 
Table 9. Directive Alerting Preference by Operation

\begin{tabular}{|l|c|c|c|}
\hline \multicolumn{1}{|c|}{ Operation } & Yes & No & $\begin{array}{c}\text { Don't } \\
\text { Know }\end{array}$ \\
\hline Runway conflict on approach & 17 & 3 & 1 \\
\hline Runway conflict on departure & 11 & 9 & 1 \\
\hline Runway conflict during taxi & 10 & 10 & 1 \\
\hline Low altitude air-to-air conflict & 19 & 2 & 0 \\
\hline Taxi conflict & 6 & 11 & 4 \\
\hline
\end{tabular}

\section{Algorithm}

Pilots provided qualitative ratings on the efficacy of onset and latency of alerting for ATCAM compared to the RTCA recommended alerts. Pilots reported a significant preference for the ATCAM algorithm for runway conflict scenarios, except for the case when on approach and following other approach traffic:

- Runway conflict on approach, $\mathrm{F}(1,48)=28.151, \mathrm{p}<.001$;

- Runway conflict while in position on runway, $\mathrm{F}(1,48)=14.240, \mathrm{p}<.001$;

- Runway conflict on departure, $\mathrm{F}(1,48)=15.534, \mathrm{p}<.001$;

- Runway conflict during taxi, $\mathrm{F}(1,48)=45.601, \mathrm{p}<.001$;

- Runway conflict on approach following traffic, $\mathrm{F}(1,48)=3.351, \mathrm{p}<.074$.

Pilots further rated the ATCAM algorithm to be significantly better for conflict prevention awareness on a binary preference comparison ranking scale with a 10-point Likert qualitative magnitude rating scale $(0=$ "no difference"; $5=$ "significant difference"; $10=$ "highly significant difference").

- Runway conflict on Approach, $(\mathrm{Z}=2.637, \mathrm{df}=48, \mathrm{p}<.001)$

- Runway conflict while in position on runway, $(\mathrm{Z}=2.776, \mathrm{df}=48, \mathrm{p}<.001)$

- Runway conflict on departure, $(\mathrm{Z}=3.0625, \mathrm{df}=48, \mathrm{p}<.001)$

- Runway conflict during taxi, $(\mathrm{Z}=2.767, \mathrm{df}=48, \mathrm{p}<.001)$

- Runway conflict on approach following traffic, $(\mathrm{Z}=2.635, \mathrm{df}=48, \mathrm{p}<.001)$
Pilot preference for ATCAM for conflict awareness was related to comparison ratings of the timeliness of the alert on a 5 -point Likert Scale $(0=$ "at about the same time"; $-2=$ "much earlier"; $+2=$ "much later") in which the ATCAM algorithm was found to be significantly earlier than the RTCA recommended algorithm timing:

- Runway conflict on approach, $(\mathrm{Z}=1.938, \mathrm{df}=24, \mathrm{p}<.001)$

- Runway conflict while in position on runway,

$$
(\mathrm{Z}=1.714, \mathrm{df}=24, \mathrm{p}<.01)
$$

- Runway conflict on departure,

$$
(\mathrm{Z}=1.621, \mathrm{df}=24, \mathrm{p}<.01)
$$

- Runway conflict during taxi, $(\mathrm{Z}=1.655, \mathrm{df}=24, \mathrm{p}<.01)$

- Runway conflict on approach following traffic, $(\mathrm{Z}=1.793, \mathrm{df}=24, \mathrm{p}<.01)$

These results were confirmed by pilot preference for a combination of ATCAM algorithm with indications compared to RTCA recommended alerting and indications:

- Runway conflict on approach, $(\mathrm{Z}=2.3100, \mathrm{df}=24, \mathrm{p}<.001)$;

- Runway conflict while in position and holding, $(\mathrm{Z}=1.980, \mathrm{df}=24, \mathrm{p}<.001)$;

- Runway conflict on departure, $(\mathrm{Z}=2.415, \mathrm{df}=24, \mathrm{p}<.001)$;

- Runway conflict during taxi, $(\mathrm{Z}=2.203, \mathrm{df}=24, \mathrm{p}<.001)$

- Runway conflict on approach following traffic, $(\mathrm{Z}=1.420, \mathrm{df}=24, \mathrm{p}<.05)$.

\section{Summary}

An initial CAAT concept for the TMA was evaluated in a simulation study. The purpose of the study was to evaluate the initial concept for an aircraft-based method of conflict detection and resolution focusing on conflict detection algorithms and alerting display concepts.

The results show that indications were found to be helpful in determining runway safety information and the location and movement of relevant traffic. However, pilot responses indicated that the descriptive terms used for indications (SI and PI) were confusing. This terminology has since been modified by RTCA SC-186 WG-1. The new 
terminology will be used and evaluated for usefulness in future research studies.

The auditory alert was rated as being most salient and useful and most likely to bring the conflict event to the pilot's attention. The results suggest that the method of display for the distance between own-ship and traffic during an alert may have limited the usefulness of the information due to the presentation method. There was variability across pilots on the actual alert phraseology that had the highest efficacy for a specified scenario although quantitative analyses allowed for discrimination of choice for each scenario. Modifications will be made to the alert displays to reflect pilot feedback.

Pilot responses indicate directive alerts are desired for both low altitude air-to-air and runway operations but not for taxi operations. These results will be further examined in upcoming simulation research. Overall, the ATCAM alerting criteria and RTCA criteria were found to be adequate for pilot response to a runway conflict. However, pilots significantly preferred the ATCAM alerting criteria to the RTCA criteria in all tested runway conflict scenarios and ATCAM was rated significantly better for conflict prevention awareness. Overall, pilots observed that the ATCAM alerted significantly earlier providing substantially more time to proactively avoid the conflict situation.

Future research will focus on optimizing the ATCAM algorithm and alerting displays based on the results of the current research and testing under an expanded set of conflict scenarios. Near-term NASA simulation research objectives involve further evaluation of directive alerting for runway, low altitude air-to-air, and taxi conflicts. The experimental methodology planned will enable the evaluation of pilot behavioral response to offnominal conflict events.

\section{References}

[1] Joint Planning \& Development Office, 2008, Next Generation Air Transportation System Integrated Work Plan: A Functional Outline, Version 1.0.

[2] Joint Planning \& Development Office, 2007, Concept of Operations for the Next Generation Air Transportation System, Version 2.0.
[3] Jones, D.R., C. C. Quach, S. D. Young, 2001, Runway Incursion Prevention System Demonstration and Testing at the Dallas/Fort Worth International Airport, Proceedings of the $20^{\text {th }}$ Digital Avionics Systems Conference.

[4] Jones, D.R., 2002, Runway Incursion Prevention System Simulation Evaluation, Proceedings of the AIAA/IEEE $21^{\text {st }}$ Digital Avionics Systems Conference.

[5] Jones, D.R., 2005, Runway Incursion Prevention System Testing at the Wallops Flight Facility, Proceedings of the SPIE Defense \& Security Symposium.

[6] Jones, D.R., L. J. Prinzel, 2006, Runway Incursion Prevention for General Aviation Operations, Proceedings of the AIAA/IEEE $25^{\text {th }}$ Digital Avionics Systems Conference.

[7] RTCA SC-186, WG-1, 2008, Enhanced Traffic Situational Awareness on the Airport Surface with Indications and Alerts (ATSA SURF IA) Operational Services and Environment Description, Draft Version 1.4.

[8] Green, D.F., February 2006, Runway Safety Monitor Algorithm for Single and Crossing Runway Incursion Detection and Alerting, NASA CR-2006214275.

[9] Green, D.F, S. D. Otero, G. D. Barker, D. R. Jones, 2009, Initial Concept for Terminal Area Conflict Detection, Alerting, and Resolution Capability On or Near the Airport Surface, NASA TM-2009-215696.

\section{$28^{\text {th }}$ Digital Avionics Systems Conference}

October 25-29, 2009 